LAWRENCE LIVERMORE N A T IO N A L LABORATORY

\title{
Field Emitter Arrays and Displays Produced by lon Tracking Lithography
}

T. E. Felter, R. G. Musket, A. F. Bernhardt

December 29, 2004

Nuclear and Instruments Methods B 
This document was prepared as an account of work sponsored by an agency of the United States Government. Neither the United States Government nor the University of California nor any of their employees, makes any warranty, express or implied, or assumes any legal liability or responsibility for the accuracy, completeness, or usefulness of any information, apparatus, product, or process disclosed, or represents that its use would not infringe privately owned rights. Reference herein to any specific commercial product, process, or service by trade name, trademark, manufacturer, or otherwise, does not necessarily constitute or imply its endorsement, recommendation, or favoring by the United States Government or the University of California. The views and opinions of authors expressed herein do not necessarily state or reflect those of the United States Government or the University of California, and shall not be used for advertising or product endorsement purposes. 
Abstract number 405 .

\title{
Field Emitter Arrays and Displays Produced by Ion Tracking Lithography
}

\author{
T. E. Felter ${ }^{1}$, R. G. Musket ${ }^{2}$, A. F. Bernhardt ${ }^{3}$
}

When ions of sufficient electronic energy loss traverse a dielectric film or foil, they alter the chemical bonding along their nominally straight path within the material. A suitable etchant can quickly dissolve these so-called latent tracks leaving holes of small diameter $(\sim 10 \mathrm{~nm})$ but long length - several microns. Continuing the etching process gradually increases the diameter reproducibly and uniformly. The trackable medium can be applied as a uniform film onto large substrates. The small, monodisperse holes produced by this track etching can be used in conjunction with additional thin film processing to create functional structures attached to the substrate. For example, Lawrence Livermore National Laboratory and Candescent Technologies Corporation (CTC) co-developed a process to make arrays of gated field emitters ( $\sim 100 \mathrm{~nm}$ diameter electron guns) for CTC's ThinCRT ${ }^{\mathrm{TM}}$ displays, which have been fabricated to diagonal dimensions > 13." Additional technological applications of ion tracking lithography will be briefly covered.

Session: Accelerators in Nanoscience an... (Thomas Schenkel)

Presentation: Cluster Poster

Keywords: "electronic stopping", "ion track", "field emitter", "latent track", nanotechnology, "flat panel display"

${ }^{1}$ Corresponding author

P O Box 808, L-356

Lawrence Livermore National Laboratory

Livermore, CA 94550 USA

e-mail: felter1@1lnl.gov

Phone: 9254228012

FAX: 9254224737

\section{${ }^{2}$ Musket Consulting}

musket6@aol.com

${ }^{3}$ Lawrence Livermore National Laboratory

Livermore, CA 94550 USA 


\section{Introduction}

For more than a half dozen years, Lawrence Livermore National Laboratory and Candescent Technologies (formerly Silicon Video Corporation) engaged in a partnership to develop field emitter array flat panel displays, FED. As the effort progressed to ever larger substrates, the various processes such as deposition and etch that are used in the fabrication steps were transferred from ones initially developed at LLNL, see Bernhardt, 2000[1], for small substrates to Candescent's facility in San Jose for large substrates. The largest substrate size employed was 320 x $340 \mathrm{~mm}$. Eventually, all processes, even high-energy ion tracking, could be performed at CTC with commercially produced tools. The beam line and associated large end station at LLNL accepts substrates up to 40 inches in diagonal $(100 \mathrm{~cm})$. The accelerator system consists of a 4 MV single ended National Electrostatics Corporation Pellatron, bending magnet, $x-y$ rastering, dosimetry system and shutter.

\section{Field Emitters Display Technology}

We briefly review the steps involved to build gated field emitter arrays, the active device in a FED. For an introduction to field emitters and vacuum microelectronics, the reader is directed to Vacuum Microelectronics, edited by Wei Zhu [2]. The completed FED is shown in Figure 1. To begin the process, a large substrate is patterned with rows and columns of metal. Each intersection of a row and column will eventually define a subpixel - i.e. one of three colors (red, green, or blue). The rows are insulated from the columns by a $\sim 100 \mathrm{~nm}$ thick silicon dioxide layer. At each subpixel, a thousand field emitter structures will be located. Figure 2 shows the process in cross section to form the field emitters. Energetic ions are directed through the top layer of polycarbonate. Each ion breaks the bonds in the polymer along its straight line trajectory. This chemical change in the polymerization of the polycarbonate drastically alternates the chemistry of the material. A suitable solution (6 molar potassium hydroxide, $\mathrm{KOH}$ ) quickly removes the altered material from each latent ion track. By continuing the etch process, the hole diameter is increased uniformly and precisely, now at a much slower rate since the material is unaltered polycarbonate. When the desired hole size is achieved, the etching of the polycarbonate layer is halted. For the CTC process, the diameter was set at $120 \mathrm{~nm}$, substantially smaller than the initial publication on this process[1].

The holes formed in the polycarbonate can now be used as a mask for plasma etching of the chrome gate metal. Any remaining polycarbonate surviving this process can be removed by dissolving in acetone. The chrome film, with holes, is used as the mask in the formation of the cavity in the underlying dielectric by anisotropic reactive ion etching using a $\mathrm{CHF}_{3} / \mathrm{O}_{2}$ gas mixture. A subsequent isotropic liquid etch using 6:1 buffered HF for 60 seconds opens the cavity further in order to prevent unwanted electrical properties that would occur during the Spindt deposition steps [3] and briefly described below.

The first deposition step creates a thin parting layer of aluminum (typically $10 \mathrm{~nm}$ ) on top of the chromium film. By performing this evaporative deposition at grazing incidence, the bottom of the cavity remains free of aluminum. The second deposition step is performed at normal incidence using e-beam evaporation of molybdenum. As 
the deposition continues, the gate hole slowly closes. This has the effect of gradually reducing the area deposited into the cavity - thereby forming a cone that is self aligned with the gate opening. Once the cone is complete - the parting layer can be removed - releasing also the molybdenum deposited onto it, yet leaving the cones of molybdenum firmly attached to the row metal film. The current geometry uses gate holes that are $120 \mathrm{~nm}$ in diameter and cones $100 \mathrm{~nm}$ high. These dimensions are three times smaller than reported in the earlier work[1].

In the FED, the array is placed under vacuum and to turn on a pixel, each molybdenum cone is biased negatively and the surrounding gate, positively. The electric field concentration at the tip is large enough to induce field emission quantum mechanical tunneling of electrons from the bulk into the vacuum region. In the Candescent device, a focussing waffle is employed to accurately direct the electrons to the inside of the face plate which is coated with phosphor materials (red, green, blue) used in ordinary CRT displays. The gap between the face plate and the emitter array is $1.2 \mathrm{~mm}$ and, during operation, the phosphor is biased at $7 \mathrm{kV}$. Because of the small size and sharpness of the tips produced, only 10 volts is needed to switch a pixel element. Brightness control is achieved by the length of time the pixel is turned on and is therefore conveniently controlled digitally.

The $51 / 2$ inch display uses the QVGA format. The pixel pitch is $0.37 \mathrm{~mm}$, the brightness is $600 \mathrm{Cd} / \mathrm{m} 2$ and the contrast ratio is $500: 1$. The power consumption is 2 watts. Thirteen inch diagonal displays have also been fabricated and the technology is scalable to much larger areas. In addition to twice the power efficiency of liquid crystal displays, the technology offers wide viewing angle, and operation at extreme temperatures (hot or cold) and no color changes when pressure is applied to the front or back surfaces by, for example, a stylus or finger. Life time is 50,000 hours, limited by the phosphor, and adequate for most applications.[4].

\section{Other examples of Ion Tracking Lithography:}

Ion tracking lithography can produce structures as small as $20 \mathrm{~nm}$ in diameter or as large as 100 microns. Ion tracking has also been shown to be viable in fused silica which affords a stronger mask material than polycarbonate [5].

Figure 3 shows an example of a simpler structure produced in the early stages of the CTC/LLNL collaboration. This "bed of nails" structure is produced by electroplating into the ion tracks. The high field emission from such structures gave the early team encouragement to develop the low voltage, gated field emitter device. The bed of nails structure can be used as a basis for more complicated devices and structures. The technique offers excellent control of important parameters and is amenable to a large number of metals, semimetals and semiconductors. Moreover, by switching the solution or the electrochemical potential, different layers can be deposited. 


\section{Conclusions:}

Ion tracking lithography has become a viable manufacturing tool for making monodisperse holes in suitable media such as free standing or deposited thin films of polycarbonate or glass. The hole diameter can be set accurately to any desired size in the range of 20 nanometers (or less) to several microns by control of the etch conditions. The length of the hole is established by the thickness of the plastic from tens of nanometers to tens of microns. Although the holes are randomly spaced, the average density can be controlled at the percent level by dosimetry techniques and are governed by simple Poisson statistics. Once the holes are formed, additional processes can be utilized such as, selective etch, electrochemical, chemical vapor, or physical deposition. A host of these processes is employed in the fabrication of field emitter arrays. Current substrates allow for 13 inch diagonal displays, but much larger substrates appear feasible.

\section{Acknowledgements:}

The development of field emitter displays involved on the order of twenty people at LLNL and even more at Candescent. Among the more significant contributors at LLNL are Alan Jankowski, Jeff Morse, and Robert Contolini. Among the large group at Candescent, T. S. Fahlen, John Macaulay, Lawrence Pan, Jack Porter, and Chris Spindt, come immediately to mind. Peter Searson at Johns Hopkins should also be acknowledged. This work was performed under the auspices of the U.S. Department of Energy by the University of California, Lawrence Livermore National Laboratory under contract No. W-7405-Eng-48.

\section{References:}

[1]. A. F. Bernhardt, R. J. Contolini, A. F. Jankowski, V. Liberman, J. D. Morse, R. G. Musket, R. Barton, J. Macaulay, and C. Spindt, Arrays of Field Emission Cathode Structures with Sub-300 nm Gates, J. Vac. Sci. and Technol. B 18, 1212 (2000)

[2]. Wei Zhu, Vacuum Microelectronics, New York, Wiley, 2001

[3]. Field-Emitter Arrays for Vacuum Microelectronics, C. A. Spindt, C. E. Holland, A. Rosengreen and I. Brodie, IEEE Transactions on Electron Devices 38, 2355, 1991. [4]. Chris Curtin, Journal of the Society for Information Displays, (2000).

[5]. R. G. Musket, J. M. Yoshiyama, R. J. Contolini, J. D. Porter, Vapor Etching of Ion Tracks in Fused Silica, J. of Appl. Phys., 91, 5760, (2002) 


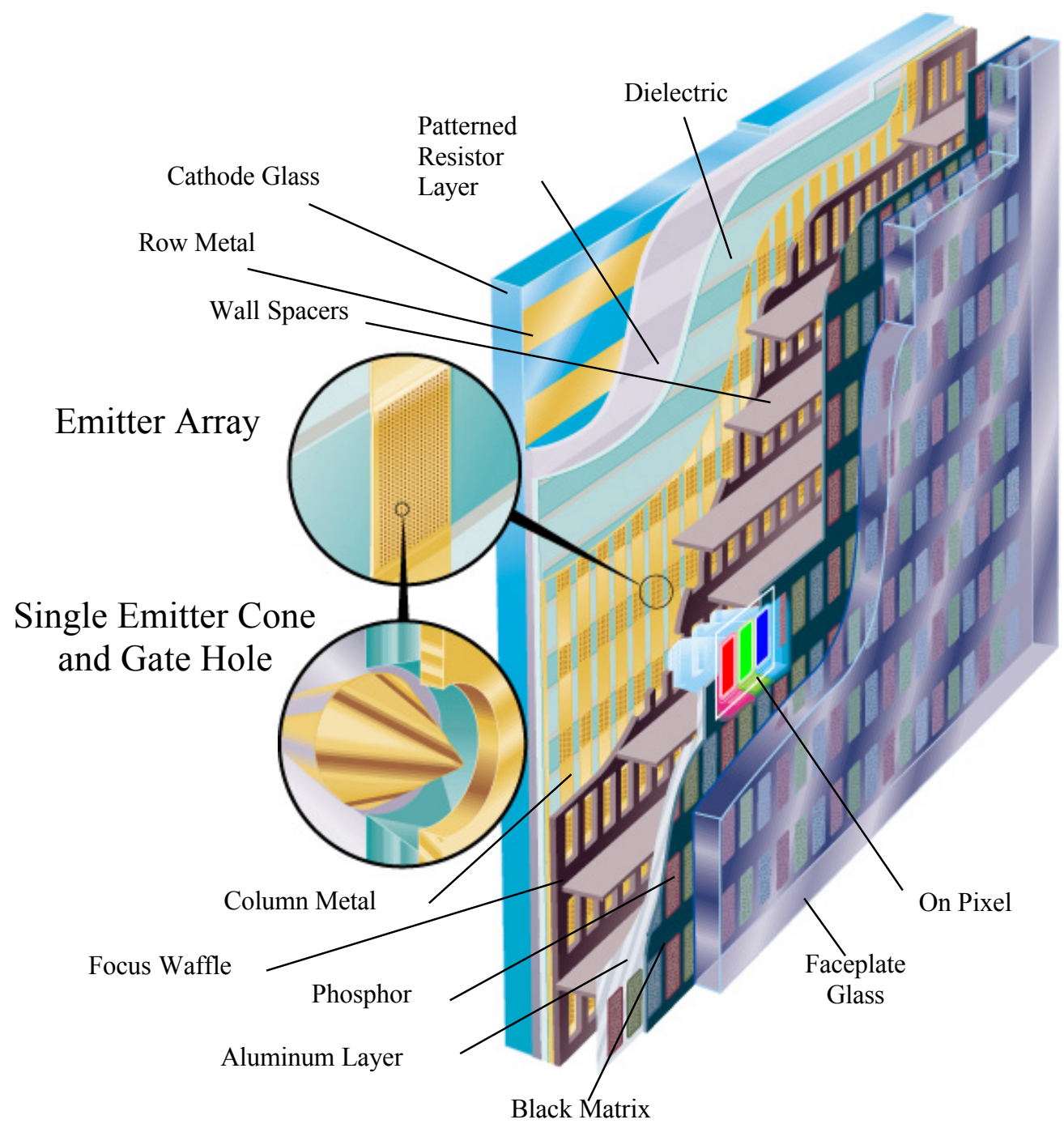

Figure 1. Exploded view of Field Emitter Display. 5 inch and 13 inch prototypes have been fabricated. 


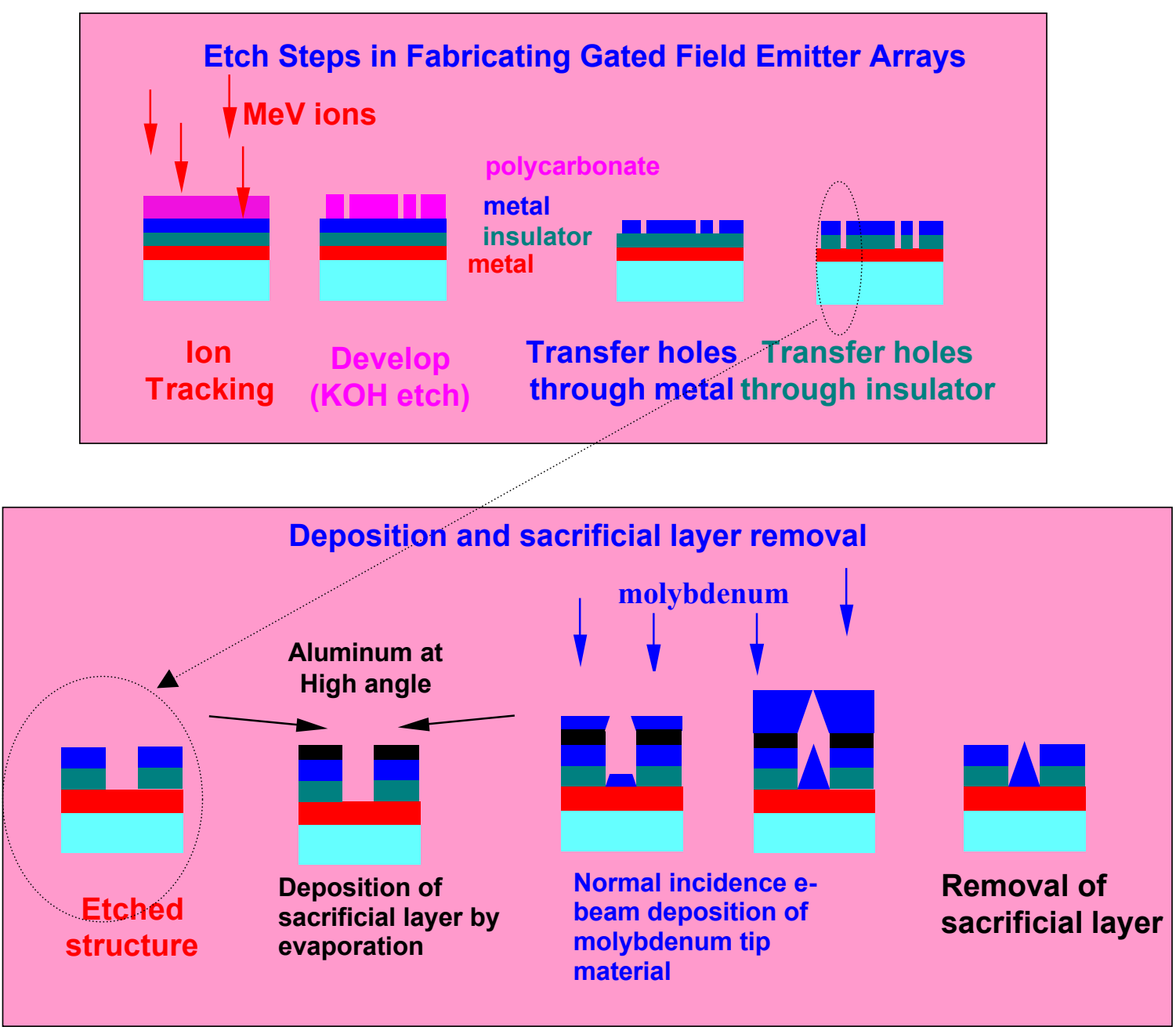

Figure 2:

Schematic of process steps to form field emitter arrays using ion tracking lithography 

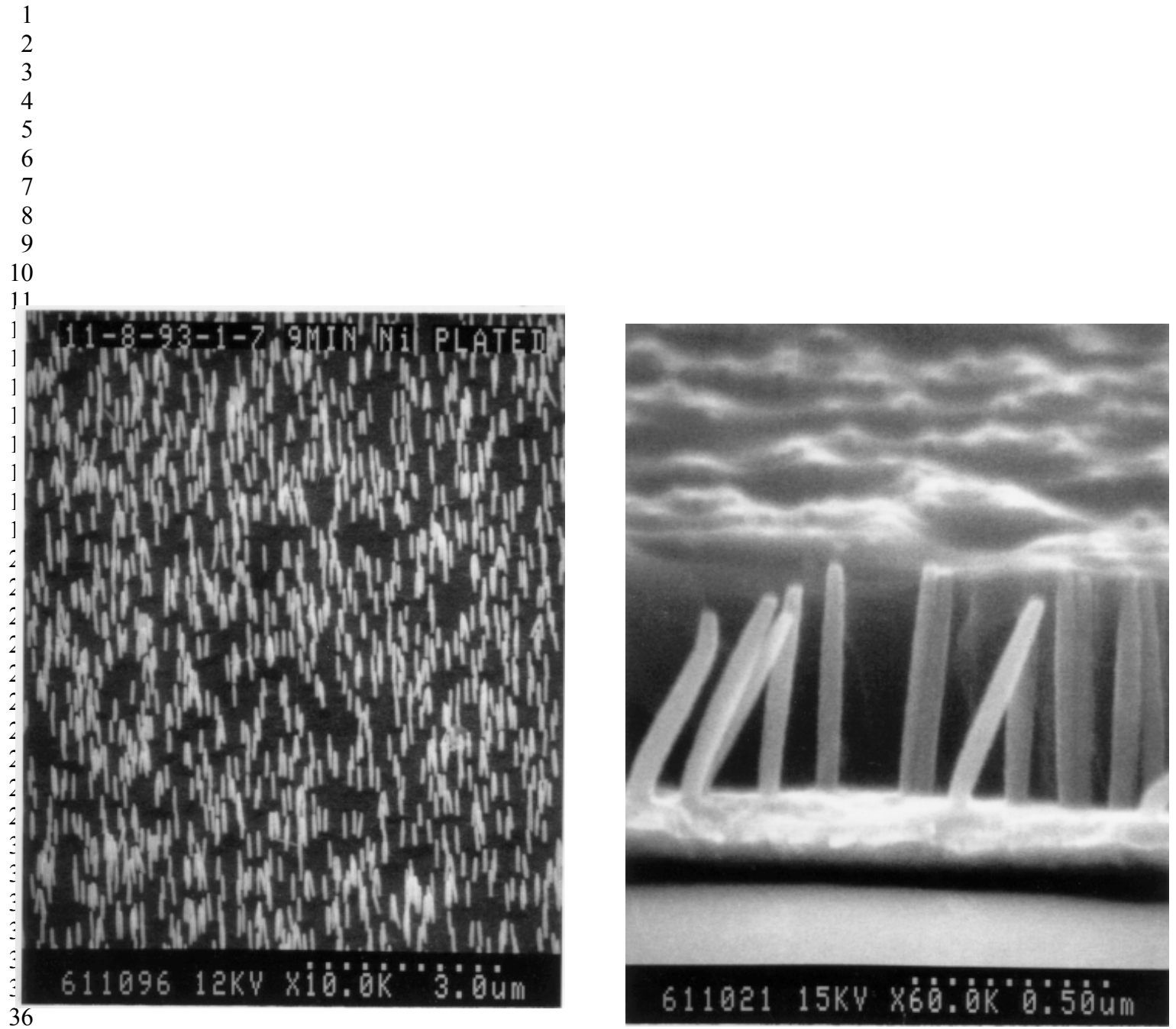

40 Figure 3: Bed of nails produced by electrodeposition of nickel into ion tracks etched 41 in polycarbonate. 